\title{
A REVIEW OF THE DISTRIBUTION AND CONSERVATION STATUS OF Chamaeleo zeylanicus LAURENTI, 1768 (REPTILIA: CHAMAELEONIDAE) IN NORTH-WESTERN SRI LANKA
}

D. M. S. Suranjan Karunarathna ${ }^{1,3}$, M. A. J. Saman Nawaratne ${ }^{1}$ and A. A. Thasun Amarasinghe ${ }^{2,4}$

${ }^{1}$ IUCN - Sri Lanka Country office, No: 53, Horton place, Colombo 07, Sri Lanka

${ }^{2}$ Taprobanica Nature Conservation Society, 146, Kendalanda, Homagama, Sri Lanka

Corresponding author: ${ }^{3}$ dmsameera@gmail.com and ${ }^{4}$ aathasun@gmail.com

\begin{abstract}
In this paper we discuss the current status of Chamaeleo zeylanicus including some observations related to the ecology, behaviour, current distribution pattern and conservation issues, based on the north-western population of the species in Sri Lanka. The area from Puttalam to Wanatha-Villuwa has the highest abundance of this species in Sri Lanka. They are deliberately killed by people in this area due to mythical beliefs and folk stories related to this species. Unplanned agricultural practices also destroy their habitats. The Sri Lankan C. zeylanicus population may be different from Indian populations and their taxonomic status has not been investigated.
\end{abstract}

Keywords: Chamaeleon, Behaviour, conservation status, distribution, Sri Lanka

\section{Introduction}

The family Chamaeleonidae consists of over 180 species belonging to six genera (Gray, 1865; Pough et al., 2004; Reptile Database, 2009), of which more than 56 species belong to the genus Chamaeleo (Halliday \& Adler, 2002; Pough et al., 2004; Tilbury \& Tolley, 2009). The genus Chamaeleo is restricted to the Old World and most of them are distributed in Madagascar and Africa, up to $4200 \mathrm{~m}$ above sea level (Halliday \& Adler, 2002). Chamaeleo zeylanicus is found in Sri Lanka, India and Pakistan in South Asia (Boulenger, 1890; Das, 1994; Das \& de Silva, 2005; Deraniyagala, 1953; Smith, 1935). Chamaeleo zeylanicus is not uncommon in India, particularly in Tamil Nadu, but it is rare in Sri Lanka (Daniel, 2002; Pethiyagoda, 1997). This species is also listed as near threatened 